\title{
A systematic review of the unit costs of allied health and community services used by older people in Australia
}

\author{
Inez Farag ${ }^{1 *}$, Cathie Sherrington ${ }^{1}$, Manuela Ferreira ${ }^{1}$ and Kirsten Howard $^{2}$
}

\begin{abstract}
Background: An economic evaluation of interventions for older people requires accurate assessment of costing and consideration of both acute and long-term services. Accurate information on the unit cost of allied health and community services is not readily available in Australia however. This systematic review therefore aims to synthesise information available in the literature on the unit costs of allied health and community services that may be utilised by an older person living in Australia.

Method: A comprehensive search of Medline, Embase, CINAHL, Google Scholar and Google was undertaken. Specialised economic databases were also reviewed. In addition Australian Government Department websites were inspected. The search identified the cost of specified allied health services including: physiotherapy, occupational therapy, dietetics, podiatry, counselling and home nursing. The range of community services included: personal care, meals on wheels, transport costs and domestic services. Where the information was not available, direct contact with service providers was made.
\end{abstract}

Results: The number of eligible studies included in the qualitative synthesis was fourty-nine. Calculated hourly rates for Australian allied health services were adjusted to be in equivalent currency and were as follows as follows: physiotherapy $\$ 157.75$, occupational therapy $\$ 150.77$, dietetics $\$ 163.11$, psychological services $\$ 165.77$, community nursing $\$ 105.76$ and podiatry $\$ 129.72$.

Conclusions: Utilisation of the Medicare Benefits Scheduled fee as a broad indicator of the costs of services, may lead to underestimation of the real costs of services and therefore to inaccuracies in economic evaluation.

Keywords: Unit costs, Allied health services, Community services

\section{Background}

A fundamental requirement for economic evaluation is accurate assessment of costing [1,2]. This allows comparative analysis of the impact of an intervention program on the costs of service utilisation and ultimately the accrued cost to benefit ratio [2]. Information on the costs of hospital and medical services is readily available [3]. For example, the costs of injuries that are associated with the most severe mortality, morbidity and hospitalisation have been established using data from hospital databases on

\footnotetext{
* Correspondence: ifarag@georgeinstitute.org.au

'George Institute for Global Health, University of Sydney, 321 Kent Street, Sydney, NSW 2006, Australia

Full list of author information is available at the end of the article
}

cost of hospital admission, cost of ambulance transport, emergency department and medical service utilisation.

An economic evaluation requires more than consideration of the acute or short term provision of services however [4]. The more widespread and longer term consequences of illness, injury and disability, with the follow-on effect of health service use, have to be considered. The difficulty in the use of available data however is that reliance on established fee schedules, for example, the Medicare Benefits Schedule in Australia [5] may not provide an accurate indication of the real cost of providing services in some clinical areas [6]; this may result in serious underestimation of the actual costs of service delivery [7]. In addition for many community services there is no established fee structure and as a

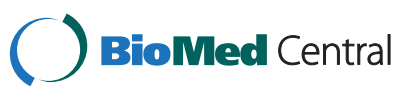


result there is great variability in the unit costs that may potentially be used in economic evaluation. To fully appreciate the cost of age-related disease and the cost effectiveness of healthcare programs, information on the cost of the full range of services utilised (including allied health and community services) is required.

The primary purpose of this systematic review, which is the first study of its type in Australia, is to provide a consolidated resource of costs of allied health and community services used by older people in Australia. This will facilitate the inclusion of these costs in future economic evaluations.

\section{Method}

\section{Literature search}

To identify the unit costs of services a comprehensive search of the databases Medline, Embase, Cumulative Index to Nursing and Allied Health Literature (CINAHL) Google Scholar and Google was conducted. In addition specialised economic databases were reviewed and accessed through the Centre for Reviews and Dissemination allowing exposure to relevant databases including Database of Abstracts of Reviews and Effects (DARE) and 11,000 economic evaluations collected in the National Health Service Economic Evaluation Database (NHSEED). It was considered that the relevant information may also be contained within government departmental literature and as such a search was conducted of Australian Government Department websites, including: NSW Department of Health, Commonwealth Department of Health and Ageing, Veteran's Affairs and the National Health and Medical Research Council. Where insufficient information was available a review of Department of Health websites of other Australian States was to be conducted. The NSW Injury Risk Management Research Centre and Australian Institute of Health and Welfare websites were also searched. The search was to identify cost of specified allied health and community services from 1980 to date. An exception to this rule was applied however, for certain databases such as Google Scholar and Google that yielded large results; to ensure feasibility, the search was limited from 2000 to date.

The allied health services that were investigated included: physiotherapy, occupational therapy, dietetics, podiatry, community nursing and counselling. Community services comprised of personal care, meals on wheels, transport services and domestic services including home cleaning, gardening services and general handyman rates. Staff travel was included as it is often a required cost item in economic evaluation. For international data, other allied health services were included, which appeared to be frequently utilised and had available costs reported. Respite care and estimates of family care costs were included as they were considered to be necessary cost items in economic evaluations. Excluded from the systematic review were ambulance, emergency department, time in hospital costs, medical practitioner consultations and residential care facility costs.

Included in the search terms were keywords: unit cost, unit price, schedule of fees, allied health services (range of terms of single professions and combined terms) and community services (range of terms of single services).

In addition the reference lists of retrieved articles were searched.

\section{Inclusion of studies}

Included were peer-reviewed published studies or publicly available reports that included an estimate of the unit cost of services. Cost of injury studies and economic analyses associated with randomised controlled trials were included if the content included information on the unit costs of services. Whilst the predominant interest is in the range of services utilised by the "older" population, papers and reports were not excluded if the relevant information on the unit costs related to the provision of similar services to a younger population.

Although the focus of the study was on Australian costs, overseas estimates were also summarised, to complement the Australian data. International costs were converted to 2011 Australian dollars using Organisation for Economic Co-operation and Development (OECD) purchasing power parities [8].

\section{Quality of included studies}

There was no limitation made or elimination of studies based on study quality as this factor did not impact on the accuracy of the unit costs utilised; often the information on unit costs was contained in the Appendix of relevant papers.

\section{Contact with service providers}

Direct contact with providers of domestic, gardening and handyman services in Australia was made to obtain the information on costs that was lacking in the literature. On average ten service providers were contacted from each category (full details of the providers contacted is available on request).

\section{Data extraction}

A standardised form was used to extract information from the published manuscripts included in the systematic review (available on request). Extracted information included: study design, cost of range of allied health and community services, source of cost item information, currency and the year of cost collection. Costs that were not relevant to the study were not incorporated. Screening of abstracts and titles and subsequent full text evaluation was conducted by IF; a sample of the manuscripts $(10 \%)$ 
were examined by two reviewers (IF, MF). Any disagreements were resolved by consensus; where consensus was not reached, input from a third examiner was sought (CS).

\section{Data synthesis}

The studies reported costs in different currencies and different years; this information was standardised by conversion to Australian dollars for the 2011 cost year. The process included conversion to Australian dollars, where necessary, using purchasing power parities [8] and inflation of the values to 2011 prices using the "health price index" [9].

Studies varied in the method of reporting unit costs, some opting to describe the cost per occasion of service [10]; whilst others describe an estimated hourly rate and others still a cost value per minute [11]. For some disciplines, such as physiotherapy and dietetics, an estimated duration was allocated to the occasion of service in some studies $[6,12]$. For other disciplines, such as psychological counselling services, sessions were described in terms of "simple" or "complex" interventions [13,14].

The unit costs of different services from the various studies and government reports were extracted. In addition a conversion to a cost per hour was made, where possible, using the estimated duration of the occasion of service provided. Where a publication provided a cost per occasion of service, this was multiplied by 2.5 (session ranging in time between 20-30 minutes), providing an average of the hourly rate charged.

Overall the methodology and reporting of this study adhere to the PRISMA guidelines for conducting qualitative systematic reviews [15].

\section{Results}

The flow chart of the search and retrieval process is displayed in Figure 1. One hundred and twenty articles were identified as being potentially relevant from the general databases and 21 from the combination of other sources. Following elimination of duplicated articles and the appraisal of titles and abstracts, 61 full text articles were identified as potentially relevant. In the final qualitative analysis twelve full-text articles were eliminated as there was a focus on aggregated rather than unit costs (five studies) and seven studies relied on unit costs from previously utilised published material. A review of the full-texts identified 49 eligible studies or reports; 28 relevant articles were derived from the general databases, sixteen papers were identified from the economic-

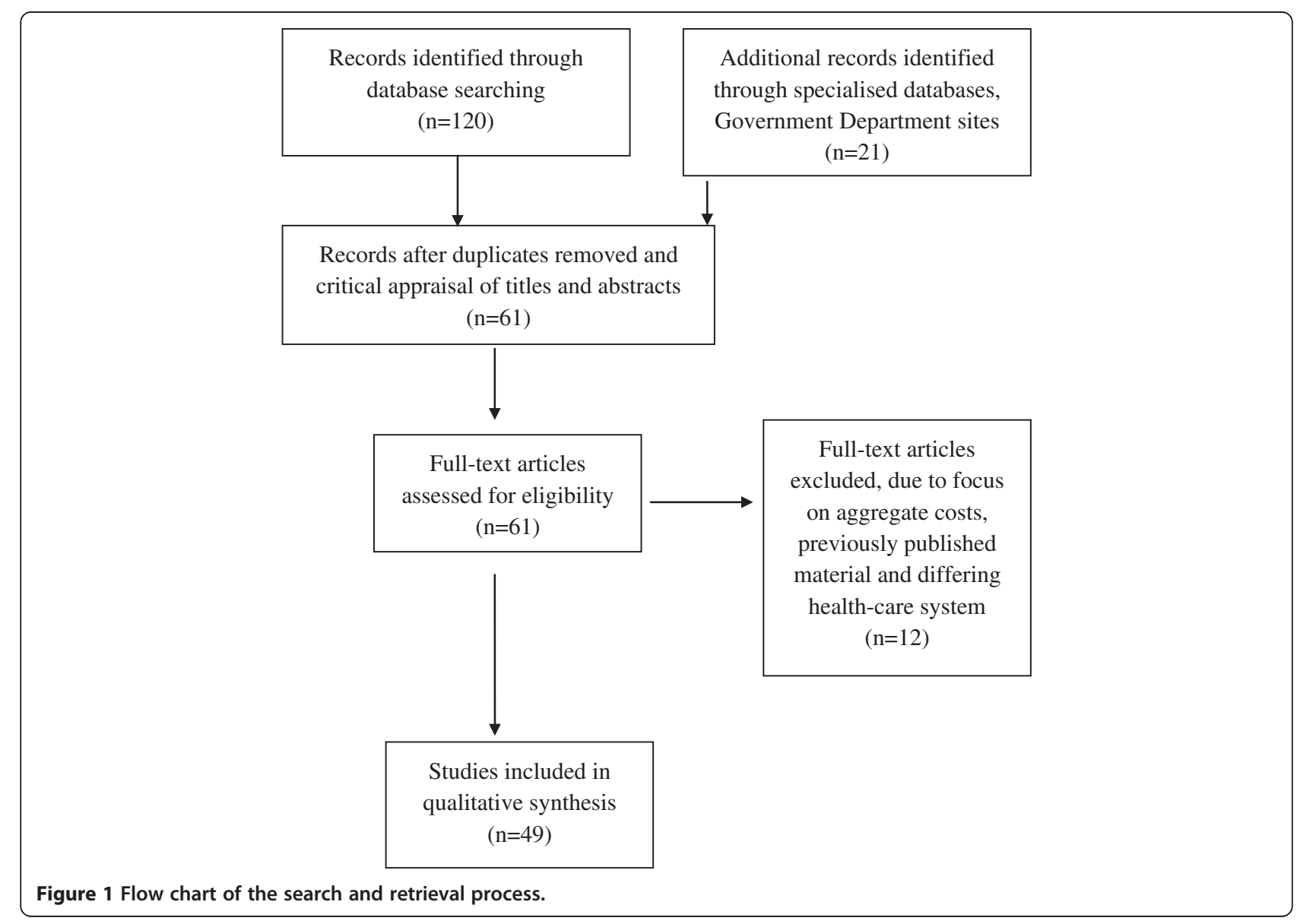


Table 1 Unit costs of allied health and community services in Australia

\begin{tabular}{ll}
\hline \multicolumn{1}{c}{ Services } & \multicolumn{1}{c}{ Cost given by individual studies 2011 \$ } \\
\hline Physiotherapy & \\
Public Hospital Service & $\$ 50.10[18], \$ 76.10[20] \$ 73.40[10], \$ 72.14[22]$ \\
Group & $\$ 29.09[23], \$ 27.35[24]$ \\
Hydrotherapy & $\$ 15.77[20], \$ 35.80[24]$ \\
Outreach & $\$ 212.19[18]$ \\
Private per visit & $\$ 76.50[19], \$ 51.44[20]$ \\
First consultation & $\$ 96.32[23], \$ 100.40[10], \$ 91.18[17], \$ 69.24[3]$ \\
Second consultation & $\$ 61.63[10], \$ 70.14[17], \$ 55.39[3]$ \\
Medicare Benefits Schedule & $\$ 59.90-F e e \$ 50.95-$ Rebate [5] \\
Special Population Veterans' Affairs & $\$ 60.53[17], \$ 61.10$ (initial \& standard) [24] $^{1}$
\end{tabular}

\section{Hourly rate}

Percentage difference between the private and the MBS fee

Fee suggested by professional association (National)

\section{Occupational Therapy}

Private per visit

Medicare Benefits Schedule

Special Population Veterans' Affairs

Group Therapy

\section{Hourly rate}

Percentage difference between the private and the MBS fee

Fee suggested by professional association (Victoria)

\section{Dietetics}

Private per visit

First consultation

Second consultation

Medicare Benefits Schedule

Special Population Veterans' Affairs

\section{Hourly rate}

Percentage difference between the private and the MBS fee

Fee suggested by professional association

$\$ 60.89[6]$

$\$ 82.28[7], \$ 105.16[17]$

$\$ 61.71[17]$

$\$ 59.90$ - Fee \$50.95- Rebate [5]

$\$ 85.30$ (initial), \$61.10 (standard) [24] ${ }^{4}$

$\$ 182.66[7]$

\section{Psychological Services}

Private per visit

Medicare Benefits Schedule

$\$ 93.56[23]$

$\$ 59.90$ - Fee $\$ 50.95$ - Rebate $[5]^{5}$
\$71.30 [23], \$76.50 [19], \$76.10 [20], \$37.81 [25], \$69.24 [3] \$64.39 per consultation (15.12) \$37.81-\$85.80 (initial), \$55.39 [3] (subsequent)

59.90-Fee $\$ 50.95$ - Rebate [5] ${ }^{2}$

$\$ 55.43$ per consultation

$\$ 61.10$ per consultation $\$ 61.10-\$ 111.25$

$\$ 21.95$ per person

\section{$\$ 150.77$ per hour}

$86-146 \%$ of the private fee

$\$ 120.00$ per consultation (expected 1 hour duration)

$\$ 60.89$ per consultation

$\$ 93.72$ per consultation (16.18)

$\$ 61.71$ per consultation

$\$ 55.43$ per consultation

$\$ 73.20$ per consultation

\section{$\$ 163.11$ per hour}

$53-91 \%$ of the private fee

Private practitioner survey $\$ 70-\$ 130$ per hour

$\$ 93.56$ per consultation
$\$ 55.43$ per consultation 
Table 1 Unit costs of allied health and community services in Australia (Continued)

\begin{tabular}{ll}
\hline Special Population Veterans' Affairs & $\frac{\text { Psychologist }}{}$ \\
& $\$ 69.35(20-50 \text { minutes })^{6}$ \\
& $\$ 97.90(50+$ minutes $)$ \\
& $\$ 146.90(90+$ minutes $)$ \\
& $\frac{\text { Clinical Psychology }}{\$ 97.90(30-50 \text { minutes })^{7}}$ \\
& $\$ 143.70(50+$ minutes $)$ \\
& $\$ 215.60(90+$ minutes
\end{tabular}

\section{Hourly rate}

Percentage difference between the private and the MBS fee

Fee suggested by professional association

\section{Community Nursing}

Private per visit

Per hour

Special Population Veterans' Affairs

\section{Hourly rate}

Percentage difference between the private and the MBS fee

Fee suggested by professional association

\section{Podiatry}

Private per visit

First consultation

Second consultation

Medicare Benefits Schedule

Special Population Veterans' Affairs

\section{Hourly rate}

Percentage difference between the private and the MBS fee

Fee suggested by professional association

\section{Staff travel}

\section{Community Services}

Personal care

Meals on wheels

Patient transport

$$
\begin{aligned}
& \frac{\text { Psychologist }}{\$ 69.35(20-50 \text { minutes) }}{ }^{6} \\
& \$ 97.90(50+\text { minutes }) \\
& \$ 146.90 \text { (90 + minutes) } \\
& \text { Clinical Psychology } \\
& \$ 97.90 \text { (30-50 minutes) }{ }^{7} \\
& \$ 143.70(50+\text { minutes }) \\
& \$ 215.60 \text { (90 + minutes }
\end{aligned}
$$

Average ${ }^{8}$ per $\mathrm{km}-0.75 \mathrm{c}$ per $\mathrm{km})^{11}$
$\$ 165.77$

$59 \%$ of the private fee

$\$ 222.00$ per one hour consultation

\$56.09 per consultation (25.85)

$\$ 60.19$ per hour (27.93)

$\$ 69.24$ [3], \$82.47 [16], \$28.85 [22]

\$40.47 (\$37.65-\$43.28) -20 minute visit

\section{$\$ 105.76$ per hour}

$80-118 \%$ of the private fee

No recommended fee by association Private agencies $\$ 46.94-\$ 69.40$ per hour

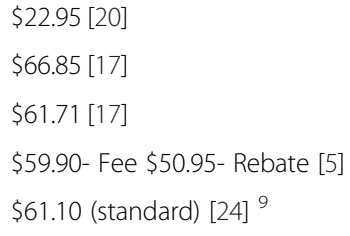

\$22.95 per consultation

$\$ 66.85$ per consultation

$\$ 61.71$ per consultation

$\$ 55.43$ per consultation

$\$ 61.10$ per consultation

$\$ 129.72$

$79-92 \%$ of the private fee

Based on market demand $(\$ 60-\$ 70$ per consultation)

0.38c per km [19], 0.73c per km [26], 0.69c per km (0.63c

\section{$0.60 \mathrm{c}$ per $\mathrm{km}(0.17)$}

$\$ 36.40$ per hour (9.6)

\$34.23 [20], \$28.07 [26], \$46.89 [16] per hour

$\$ 11.10$ per meal (7.71)

$\$ 6.56$ per meal [20], \$20.00 [16], \$6.75 (\$4.50-\$9.00) ${ }^{10}$

$\$ 12.39$ per trip (8.25)
$\$ 6.56$ per trip (council/hospital provided) [20], \$18.22 per trip [16] 


\section{Table 1 Unit costs of allied health and community services in Australia (Continued)}

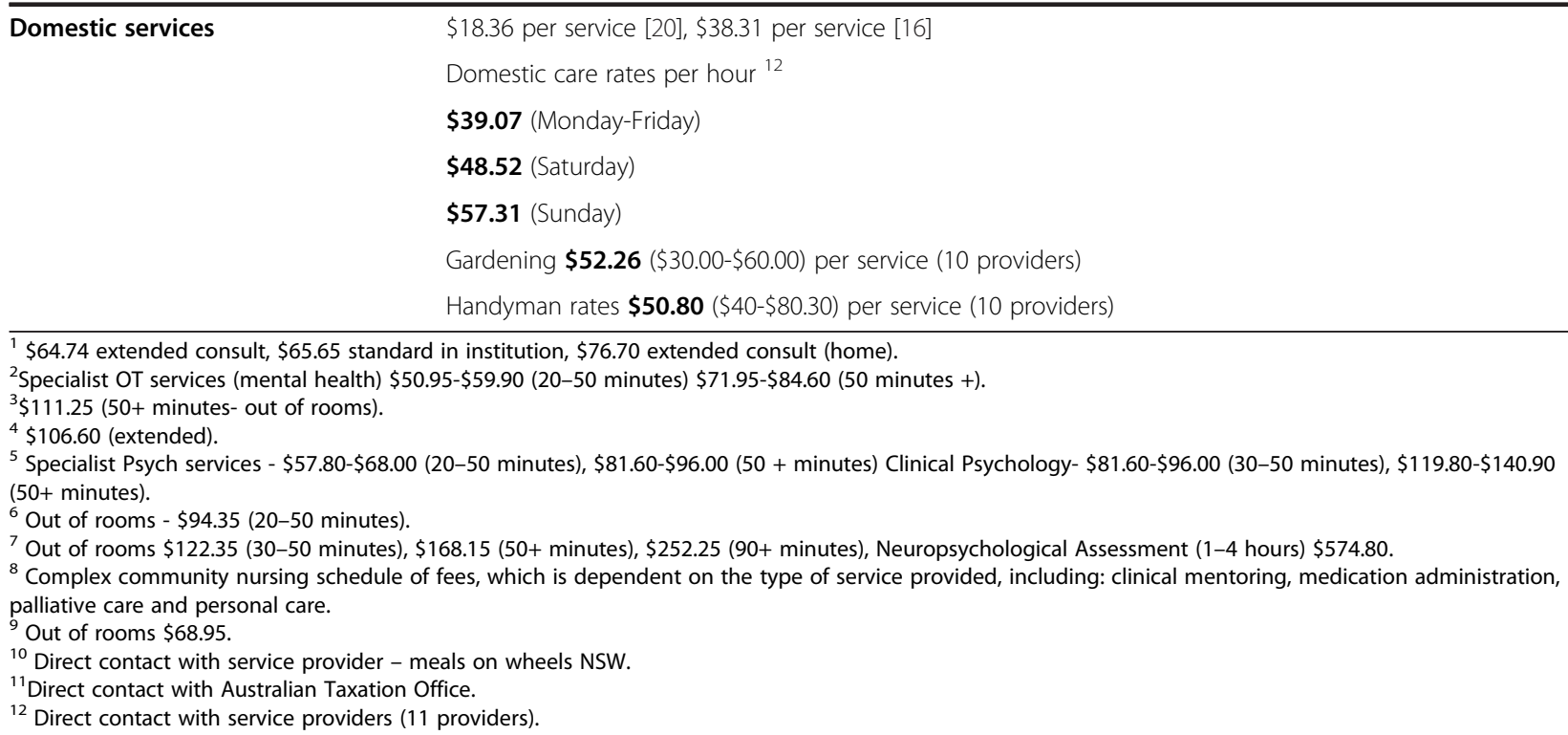

specific databases and two publications were identified as relevant from Australian government department websites. A review of the reference lists of obtained articles yielded three studies of relevance.

\section{Study characteristics}

Of the eligible studies 15 were Australian based, 18 were based in the United Kingdom, 9 based in other countries of the European Union, 3 based in the United States, 1 based in Canada, 1 based in Hong Kong and 2 were based in New Zealand.

Of the 15 Australian based studies/reports, seven (47\%) were published prior to the year 2000, the first study in 1989 [16] (published in 1996). Many of the Australian studies could be described as descriptive reviews and case studies $(n=5)$, the remainder having the following study design: cost of injury studies $(n=3)$, resource utilisation studies $(\mathrm{n}=2)$, economic evaluations $(\mathrm{n}=2)$, decision analysis modelling $(\mathrm{n}=1)$ and Government Department Schedule of Fees $(n=2)$. Equal number of studies described the unit costs on an hourly basis as per session/visit basis $(n=5)$; whereas at least four distinguished between the cost of an initial consultation and subsequent visits $[3,6,10,17]$. Several studies included information from local service providers and were specific to a particular environmental context $[18,19]$; this affects the ability to generalise the information to an alternate setting. Others derived costs from surveys of private practitioners $[6,17,20]$ and here the validity of the cost estimates was influenced by the size of the study.

Most of the economic evaluations retrieved from the specialised databases $(n=16)$ were conducted in the
United Kingdom ( $\mathrm{n}=11,69 \%)$; these varied in relation to the comprehensiveness of the economic evaluations conducted. Several studies tended to rely on unit costs on the established work of Curtis \& Netten [21].

\section{Unit costs of services in Australia}

Table 1 contains the unit costs of a range of allied health and community services in Australia. The calculated hourly rates for allied health services were within the range \$105.67 (community nursing) to \$165.77 (psychological counselling services). The results suggest considerable variety in the costs charged by private practitioners of allied health services in Australia. For all practitioners a higher fee is charged for the first consultation, than for subsequent visits. The costs charged are closely associated with the nature of the service provided and whether it is, for example, provided in the home environment or as part of a group intervention.

An average duration per occasion of service has been clarified for the disciplines of physiotherapy and dietetics $[5,6,24]$ and is estimated to be between 20-30 minutes; but is less clear for other disciplines. Session duration appears to have an impact on the service costs $[5,24]$ whether this is expressed in terms of the time taken per session as for physiotherapy or in the complexity of the intervention required, as for counselling [14].

The Medicare Benefits Schedule fee is lower than the private set fee for most disciplines. The percentage discrepancy between the MBS fee and the private fee is greatest for psychological services at 59\% and lowest for community nursing $80-118 \%$ (Table 1). There is indication however of flexibility in fee structure in the private setting to accommodate special populations, including 
Table 2 Unit costs of allied health and community services in selected countries

Service

United Kingdom

Counselling

$\$ 77.89[31], \$ 111.25[31]^{1}$

Home care

\$19.16 [31], \$44.23 [32], \$17.75 [33], \$24.31 [34], \$27.72 [35]

Podiatry

\$46.97 [32], \$28.70 [36], \$53.67 [35]

Dietetics

Home nursing

$\$ 135.67$ [32]

Physiotherapy

$\begin{array}{ll} & {[12]^{4}, \$ 54.00[44]} \\ & \$ 62.48 \text { per hour [21] } \\ & \$ 104.14[42]^{5}, \$ 45.40[34], \$ 34.22[21]^{6}, \$ 45.34[12], \$ 106.97 \\ & \$ 83.30[21]^{7} \\ & \$ 161.39[37] \\ & \$ 106.97[32], \$ 24.29[35], \$ 45.32[34] \text { 547.88 [45] per day, } \\ \text { Occupational } & \\ \text { Therapy } & \$ 216.55[32], \$ 278.61[35] \\ \text { Social Work } & \$ 43.82[34] \\ \text { Speech Pathology } & \$ 99.14[32], \$ 96.40[35]{ }^{8} \\ \text { Meals } & \$ 5.87[35], \$ 9.82[34] \\ \text { Family care } & \$ 26.78[34] \\ \text { Respite care } & \$ 254.32[30] \text { (NHS), \$63.57 (VS), \$117.86 (LCA) [30] }{ }^{10}\end{array}$

\section{Europe}

Home care

Home Nursing

Physiotherapy

Occupational

Therapy

Staff travel

Meals

Cleaning

\section{United States}

Counselling

Home care

Home nursing

Physiotherapy

Social work

Family care

\section{Canada}

Home care

Home nursing

Physiotherapy

Occupational

Therapy
\$25.67 [29] (FR), \$34.01 [29] (GR), \$30.32 [29] (UK), \$48.57 [46], \$52.64 [47], $\$ 55.21[48]$

$\$ 60.15[49]$

$\$ 35.05[50], \$ 80.20[49], \$ 137.95[46], \$ 65.87[51], \$ 151.64[47]$

$\$ 85.49[46]^{11}, \$ 76.44[47], \$ 36.75[52]^{12}$

$\$ 50.13[53], \$ 65.87[51], \$ 94.47[48]$

$\$ 94.47[48], \$ 99.09[46]^{13}$

$\$ 50.13[53], \$ 65.87[51]$

0.38c per km [50], 0.36c per km [53]

$\$ 14.03$ [49]

$\$ 54.13[49]$

$\$ 179.40$ [14] per occasion of service

$\$ 10.36$ [54] per hour

$\$ 35.00$ [54] per hour

$\$ 32.96$ [54] per occasion of service

\$26.04 [54] per hour

$\$ 8.64[54], \$ 20.41[55]$
Mean (SD), range

\$94.57 per consultation (23.59) \$77.89-\$111.25

$\$ 26.63$ per hour (13.04) \$17.75-\$44.23

$\$ 43.11$ per consultation (12.92) \$28.70-\$53.67

$\$ 135.67$ per consultation

\$54.90 per consultation (29.13) \$34.50-\$112.42

(NHS) \$41.08 per consultation (13.77) \$24.29$\$ 64.23$

(NHS) \$62.48 per hour

(Private) \$74.81 per consultation (32.19) $\$ 34.22-\$ 104.14$

(Private) $\$ 161.39$ per hour

\$58.86 per consultation (42.97) \$24.29-\$106.97

\$247.58 per consultation (43.88)

$\$ 43.82$ per consultation

$\$ 97.77$ per hour (1.94)

$\$ 7.85$ per meal (2.82)

$\$ 26.78$ per hour

\$145.25 per day (98.28) \$63.57-\$254.32

\$41.07 per consultation (12.59) \$25.67-\$55.21

$\$ 60.15$ per hour

\$94.14 per consultation (49.27 \$35.05-\$151.64 $\$ 66.23$ per consultation (25.93) \$36.75 -\$85.49 $\$ 70.16$ per hour - public (22.48) \$50.13-\$94.47 $\$ 96.78$ per consultation (3.27)

$\$ 58.00$ per hour- public (11.13) \$50.13-\$65.87

0.37c per km (.01) 0.36-0.38c per km

$\$ 14.03$ per meal

$\$ 54.13$ per hour

\$179.40 per consultation

$\$ 10.36$ per hour

$\$ 35.00$ per hour

$\$ 32.96$ per consultation

\$26.04 per hour

$\$ 14.53$ per hour (8.32) \$8.64-\$20.41

$\$ 26.53$ per hour

$\$ 67.56$ per consultation

$\$ 111.21$ per consultation

$\$ 138.32$ per consultation 
Table 2 Unit costs of allied health and community services in selected countries (Continued)

\begin{tabular}{|c|c|c|}
\hline \multicolumn{3}{|l|}{ Hong Kong } \\
\hline Home nursing & $\$ 65.11[57]$ & $\$ 65.11$ per consultation -public \\
\hline \multicolumn{3}{|l|}{ New Zealand } \\
\hline Home nursing & $\$ 20.80[58]$ & $\$ 20.80$ per hour \\
\hline Physiotherapy & $\$ 24.22[58]$ & $\$ 24.22$ per hour \\
\hline $\begin{array}{l}\text { Occupational } \\
\text { Therapy }\end{array}$ & $\$ 27.85[59]$ & \$27.85 per consultation-public \\
\hline Staff travel & 0.78 per km [58], 0.69 per km [59] & $0.74 \mathrm{c}$ per $\mathrm{km}(.06)(0.69-0.78) \mathrm{c}$ per $\mathrm{km}$ \\
\hline $\begin{array}{l}{ }_{1} \text { cost dependent } \\
{ }^{2} \text { Service is } 20 \mathrm{~min} \\
{ }^{3} \text { Initial consultatic } \\
{ }^{4} \text { Service is } 20 \mathrm{mi} \\
{ }^{5} \text { Initial consultatic } \\
{ }^{6} 20 \text { minute servi } \\
{ }^{7} \text { Clinical specialist } \\
{ }^{8} \$ 1.94 \text { per minut } \\
{ }^{9} \text { Initial consultati } \\
{ }^{10} \text { Cost is depende } \\
{ }^{11} \$ 101.03 \text { for hor } \\
{ }^{12} \text { Service is } 30 \mathrm{~m} \\
{ }^{1301.03} \text { for hon }\end{array}$ & $\begin{array}{l}\text { level of complexity of the case. } \\
\$ 32.10 \text { subsequent visits. } \\
\text { es, Home visit } \$ 111.27 \text {. } \\
\$ 87.72 \text { subsequent visits. } \\
\text { peech pathology) and } \$ 2.48 \text { per minute (Home nursing). } \\
\$ 87.72 \text { subsequent visits. } \\
\text { on provider of service, NHS, voluntary sector or local council authority. } \\
\text { visit. } \\
\text { tes in duration. } \\
\text { visit. }\end{array}$ & \\
\hline
\end{tabular}

clientele of the Department of Veterans' Affairs and those supported by the Medicare Benefits Scheme.

There are other factors that impact on costing. Public hospital services, for example, are generally costed at a lower rate in comparison to private practitioner fees $[18,20]$. For some disciplines specialist qualifications are compensated at a higher rate by the Medicare Benefits Scheme (MBS) whereas for nursing services, cost is dependent on the complexity of services provided [24]. There has been a steady increase in the cost of service delivery for all allied health services. The percentage increase in physiotherapy being an increase of $4.00 \%$ during 2011-2012, in comparison to an increase of $2.6 \%$ during 2010-2011 [27]. Most of the professional associations choose not to become involved in fee setting (Dietitians Association of Australia) but do provide members with information on average fees charged by private practitioners of their discipline (Table 1). The Australian Psychological Society produces a schedule of recommended fees for psychological services [28].

Patient transport costs were dependent on subsidy from local or health services [20]. Domestic services, including home cleaning, gardening and handyman services are greatly influenced by the time of service delivery, with higher rates charged for work conducted on Saturday and Sunday.

\section{International unit costs of services}

Many of the studies were conducted in the United Kingdom and most utilised the reference document developed by Netten \& Curtis [21], which categorises in considerable detail the unit costs of health services. The results of the unit costs for the international data are contained in Table 2 . There is variability in the costs of allied health and community services between countries, including across countries of the European Union. The work of Lafuma [29] highlights the different costs attributed to home care services between, Italy, France, Germany and The United Kingdom. International data included a wider range of reported allied health service costs with information available on the costs of social work and speech pathology. Respite care was a reported cost item in the United Kingdom, whereas estimates of the cost of family care were available for the United Kingdom and the United States. Respite care costs in the United Kingdom are highly variable and dependent on subsidy from health or local services [30].

\section{Discussion}

The costs of allied health and community services are a significant component of the total cost of illness, injury and disability for the older person [56] and often these costs are overlooked in economic evaluation. Accurate estimation of the unit costs of services specific to the nature and type of service provided, for example whether it is a group service, first consultation or provided by the public health sector, allows for a more precise calculations of the costs incurred.

The results of this review suggest variability in the cost structure of allied health services in Australia. Whilst the Medicare Benefits Schedule fee is at the lower end of the fee structure with noted discrepancies in the percentage differences between the differing disciplines, there is suggestion of flexibility within the private health sector to cater for special populations [17]. Nevertheless reliance on the fee established by the Medicare Benefits Scheme in 
estimation of the costs of allied health services in economic evaluation may lead to a serious underestimation of the cost of services, with sometimes as much as double the cost being charged, in the private sector, for a particular service [7].

The results of this review also suggest a link between the time spent by the practitioner and the costs of the services provided. Whilst, often this is expressed in terms of session duration, it may also be reflected in the setting where service provision occurs; for example, outreach physiotherapy services.

There was little information available in the literature on the cost of domestic services including home cleaning, garden maintenance or handyman activities. Contact with service providers indicated that the cost is highly dependent on the time of service provision. Whilst many were prepared to offer a range of the costs and averages of the cost of service have been provided, most stipulated that they would prefer to give a quote estimate when they actually value the work required in the job.

The differences in the cost of services between countries may be attributed to the societal value attributed to particular disciplines and the historical development of the health care system in each country. There is some similarity between the United Kingdom and Australia in the costs of some of the allied health services but the contribution of disciplines has evolved and developed to varying extents in the different communities, with a slightly different focus in terms of particular discipline intervention. An example of this is in the United Kingdom, which tends to highly value the cost of social work services in comparison to the United States, which places a significantly lower hourly rate $[11,32,54]$.

The following limitations have to be considered for this review. Our aim was to specifically synthesise information on costs of allied health and community services in the Australian context, so necessarily, our review has focussed on Australia. For many of the services in the US, Canada, countries of the European Union and New Zealand only peer-reviewed literature sources have been included, whereas for Australia a more comprehensive search has been conducted to include Government reports and established scheduled fee documents.

It should be acknowledged that some smaller studies relied on reported cost estimates from a limited group of service providers in their local setting. This has an impact on the validity of the cost estimates. In addition, where the costs reported were specific to a particular environmental context, there is impact on the ability to generalise the information gathered.

The comprehensiveness of the economic evaluations also varied. This it was felt did not markedly impact on the accuracy of the unit costs reported, as many studies referred to pre-established unit costs of services that were derived from alternate sources, external to the actual study.

Further research is recommended to explore the difference in the fees charged across different regions in Australia and to determine the impact of setting and workforce supply issues on the cost structure of services.

\section{Conclusion}

Economic evaluations require consideration of the costs of total health service use. Accurate estimation of the range of allied health and community services is essential in determining the cost-effectiveness of intervention and prevention programmes. Utilisation of Government established fee schedules as a broad indicator of the cost of services may lead to underestimation of the real costs of services and therefore to inaccuracies in economic evaluation.

\section{Competing interests}

The authors declare that they have no competing interests.

\section{Authors' contribution}

IF carried out the database search, screened the titles and abstracts, the full text articles and drafted the manuscript. MF Assisted with the database search activities, in the screening of the sample of full text articles and in the drafting of the manuscript. CS Conceived of the study and participated in its design and coordination and helped to draft the manuscript. KH Participated in the design of the study provided technical expertise and helped to draft the manuscript. All authors read and approved the final manuscript.

\section{Acknowledgements}

CS and MF receive salary support from the NHMRC. IF is supported by a scholarship funded by the NHMRC.

\section{Author details}

${ }^{1}$ George Institute for Global Health, University of Sydney, 321 Kent Street, Sydney, NSW 2006, Australia. ${ }^{2}$ Sydney School of Public Health, University of Sydney, Sydney, NSW 2006, Australia.

Received: 4 July 2012 Accepted: 19 February 2013

Published: 20 February 2013

\section{References}

1. Drummond MF: Methods for the economic evaluation of health care programmes. 3rd edition. Oxford: Oxford University Press; 2005.

2. Johannesson M: Theory and methods of economic evaluation of health care. Dev Health Econ Public Policy 1996, 4:1-245.

3. Tiedemann AC, Murray SM, Munro B, Lord SR: Hospital and non-hospital costs for fall-related injury in community-dwelling older people. N S W Public Health Bull 2008, 19(9-10):161-165.

4. Alastair Gray PC, Wolstenholme J, Wordsworth S: Applied Methods of Costeffectiveness Analysis in Health Care. New York: Oxford University Press; 2011.

5. Department of Health and Ageing: Medicare, Medicare Benefits Schedule, 2010-2012, Commonwealth of Australia Canberra ACT. 2012. http://www. medicareaustralia.gov.au/provider/medicare/mbs.jsp (Accessed 07.05.12).

6. Cant R, Aroni R: Melbourne dietitians' experience of medicare policy on allied health services (strengthening medicare; enhanced primary care) in the first 12 months. Nutr Diet 2007, 64(1):43-49.

7. Cant RP: Public health nutrition: The accord of dietitian providers in managing medicare chronic care outpatients in Australia. Int J Environ Res Public Health 2010, 7(4):1841-1854

8. Organisation for Economic Cooperation and Development (OECD). 2012. PPPs and Exchange rates. http://stats.oecd.org/Index.aspx?datasetcode=PPPGDP TABLE 4 (Accessed 05.05.12).

9. Australian Institute of Health and Welfare: Health expenditure Australia, 2008-2009. Commonwealth of Australia, Canberra ACT. 2010. http://www. 
aihw.gov.au/workarea/Download.Asset.aspx?id=6442473791 (Accessed 07.05.12).

10. Neumann PB, Grimmer KA, Grant RE, Gill VA: The costs and benefits of physiotherapy as first-line treatment for female stress urinary incontinence. Aust N Z J Public Health 2005, 29(5):416-421.

11. Patel A, Knapp M, Evans A, Perez I, Kalra L: Training care givers of stroke patients: economic evaluation. BMJ 2004, 328(7448):1102.

12. Whitehurst DGT, Lewis M, Yao GL, Bryan S, Raftery JP, Mullis R, Hay EM: A brief pain management program compared with physical therapy for low back pain: results from an economic analysis alongside a randomized clinical trial. Arthritis Rheum 2007, 57(3):466-473.

13. Donisi V, Jones J, Pertile R, Salazzari D, Grigoletti L, Tansella M, Amaddeo F: The difficult task of predicting the costs of community-based mental health care. A comprehensive case register study. Epidemiol Psychiatr Sci 2011, 20(3):245-256.

14. Rosenheck $R$, Neale M, Frisman $L$ : Issues in estimating the cost of innovative mental health programs. Psychiatr Q 1995, 66(1):9-31.

15. LA Moher D, Tetzlaff J, Altman D: Preferred Reporting Items for Systematic Reviews and Meta-Analyses: The PRISMA Statement. PLoS Med 2009, 6(7):1-6.

16. McCallum J, Simons L, Simons J, Wilson J, Sadler P, Owen A: Patterns and costs of post-acute care: a longitudinal study of people aged 60 and over in Dubbo. Aust N Z J Public Health 1996, 20(1):19-26.

17. Pearce-Brown CL, Grealish L, McRae IS, Douglas KA, Yen LE, Wells RW, Wareham S: A local study of costs for private allied health in Australian primary health care: Variability and policy implications. Aust J Prim Health 2011, 17(2):131-134

18. Allen O: Anthill and other injuries: a case for mobile allied health teams to remote Australia. Aust J Rural Heal 1996, 4(1):33-42.

19. Hassall S, Wootton R, Guilfoyle $C$ : The cost of allied health assessments delivered by videoconference to a residential facility for elderly people. J Telemed Telecare 2003, 9(4):234-237.

20. Hall SE, Hendrie DV: A prospective study of the costs of falls in older adults living in the community. Aust N Z J Public Health 2003, 27(3):343-351.

21. Curtis L, Netten A: Unit costs of health and social care. Kent: University of kent; 2006

22. Moore KH, O'Sullivan RJ, Simons A, Prashar S, Anderson P, Louey M: Randomised controlled trial of nurse continence advisor therapy compared with standard urogynaecology regimen for conservative incontinence treatment: efficacy, costs and two year follow up. BJOG 2003, 110(7):649-657.

23. Cleary MI, Murray JM, Michael R, Piper K: Outpatient costing and classification: Are we any closer to a national standard for ambulatory classification systems? Med J Aust 1998, 169(SUPPL):S26-S31.

24. Department of Veterans' Affairs: 2012. Schedule of fees. January 2012. Commonwealth of Australia, Canberra ACT. http://www.dva.gov.au/ service_providers/Pages/index.aspx?Pages/Fee_schedulejan2012.aspx (Accessed 07.05.2012).

25. Smith RD, Widiatmoko D: The cost-effectiveness of home assessment and modification to reduce falls in the elderly. Aust N Z J Public Health 1998, 22(4):436-440

26. Smith CS, Crowley S: Labor force planning issues for allied health in Australia. J Allied Health 1995, 24(4):249-265.

27. Pont MCA: 2012 Assessment of Market Rates for Physiotherapy Services. Melbourne, Australia: Millward Brown; 2012:8-20.

28. Schedule of recommended fees and items numbers for psychological services. Australian Psychological Society; 2012. http://www.psychology.org.au/ search.aspx?SearchText=Schedule+of+recommended+fees (Accessed 07.05.2012)

29. Lafuma A, Brezin A, Lopatriello S, Hieke K, Hutchinson J, Mimaud V, Berdeaux G: Evaluation of non-medical costs associated with visual impairment in four European countries: France, Italy, Germany and the UK. Pharmacoeconomics 2006, 24(2):193-205.

30. Mason A, Weatherly H, Spilsbury K, Arksey H, Golder S, Adamson J, Drummond $\mathrm{M}$, Glendinning C: A systematic review of the effectiveness and cost-effectiveness of different models of community-based respite care for frail older people and their carers. Health Technol Assess 2007, 11(15):1-157.

31. Chisholm D, Godfrey E, Ridsdale L, Chalder T, King M, Seed P, Wallace P, Wessely S, Fatigue Trialists G: Chronic fatigue in general practice: economic evaluation of counselling versus cognitive behaviour therapy. Br J Gen Pract 2001, 51(462):15-18.
32. Flood C, Mugford M, Stewart S, Harvey I, Poland F, Lloyd-Smith W: Occupational therapy compared with social work assessment for older people. An economic evaluation alongside the CAMELOT randomised controlled trial. Age Ageing 2005, 34(1):47-52.

33. O'Shea E, Blackwell J: The relationship between the cost of community care and the dependency of old people. Soc Sci Med 1993, 37(5):583-590.

34. Saka O, Serra V, Samyshkin Y, McGuire A, Wolfe CCDA: Cost-effectiveness of stroke unit care followed by early supported discharge. Stroke 2009, 40(1):24-29

35. Patel A, Knapp M, Perez I, Evans A, Kalra L: Alternative strategies for stroke care: cost-effectiveness and cost-utility analyses from a prospective randomized controlled trial. Stroke 2004, 35(1):196-203.

36. Waxman R, Woodburn H, Powell M, Woodburn J, Blackburn S, Helliwell P: FOOTSTEP: A randomized controlled trial investigating the clinical and cost effectiveness of a patient self-management program for basic foot care in the elderly. J Clin Epidemiol 2003, 56(11):1092-1099.

37. Richardson G, Hawkins N, McCarthy CJ, Mills PM, Pullen R, Roberts C, Silman A, Oldham JA: Cost-effectiveness of a supplementary class-based exercise program in the treatment of knee osteoarthritis. Int J Technol Assess Health Care 2006, 22(1):84-89.

38. Raftery JP, Addington-Hall JM, MacDonald LD, Anderson HR, Bland JM Chamberlain J, Freeling P: A randomized controlled trial of the costeffectiveness of a district co-ordinating service for terminally ill cancer patients. Palliat Med 1996, 10(2):151-161.

39. Walsh B, Steiner A, Pickering RM, Ward-Basu J: Economic evaluation of nurse led intermediate care versus standard care for post-acute medical patients: cost minimisation analysis of data from a randomised controlled trial. BMJ 2005, 330(7493):699.

40. Team UBT: United Kingdom back pain exercise and manipulation (UK BEAM) randomised trial: effectiveness of physical treatments for back pain in primary care. BMJ 2004, 329(7479):1377

41. Rivero-Arias O, Gray A, Frost H, Lamb SE, Stewart-Brown S: Cost-utility analysis of physiotherapy treatment compared with physiotherapy advice in low back pain. Spine 2006, 31(12):1381-1387.

42. Klaber Moffett JA, Jackson DA, Richmond S, Hahn S, Coulton S, Farrin A, Manca A, Torgerson DJ: Randomised trial of a brief physiotherapy intervention compared with usual physiotherapy for neck pain patients: outcomes and patients' preference. BMJ 2005, 330(7482):75.

43. Struijs PAA, Korthals-de Bos IBC, van Tulder MW, van Dijk CN, Bouter LM, Assendelft WJJ: Cost effectiveness of brace, physiotherapy, or both for treatment of tennis elbow. Br J Sports Med 2006, 40(7):637-643. discussion 643.

44. Thomas KS, Miller P, Doherty M, Muir KR, Jones AC, O'Reilly SC: Cost effectiveness of a two-year home exercise program for the treatment of knee pain. Arthritis Rheum 2005, 53(3):388-394.

45. Schneider J, Duggan S, Cordingley L, Mozley CG, Hart C: Costs of occupational therapy in residential homes and its impact on service use. Aging Ment Health 2007, 11(1):108-114.

46. Borgstrom F, Zethraeus N, Johnell O, Lidgren L, Ponzer S, Svensson O, Abdon P, Ornstein E, Lunsjo K, Thorngren $K G$, et al: Costs and quality of life associated with osteoporosis-related fractures in Sweden. Osteoporos Int 2006, 17(5):637-650.

47. Janzon M, Levin LA, Swahn E: Cost-effectiveness of an invasive strategy in unstable coronary artery disease; results from the FRISC II invasive trial. The Fast Revascularisation during InStability in Coronary artery disease. Eur Hear J 2002, 23(1):31-40.

48. Claesson L, Gosman-Hedstrom G, Johannesson M, Fagerberg B, Blomstrand $C$ : Resource utilization and costs of stroke unit care integrated in a care continuum: A 1-year controlled, prospective, randomized study in elderly patients: the Goteborg 70+ Stroke Study. Stroke 2000, 31(11):2569-2577.

49. Hammar T, Rissanen P, Perala M-L: The cost-effectiveness of integrated home care and discharge practice for home care patients. Health Policy 2009, 92(1):10-20.

50. Annemans L, Van Overbeke N, Standaert B, Van Belle S: Estimating resource use and cost of prophylactic management of neutropenia with filgrastim. J Nurs Manag 2005, 13(3):265-274.

51. Kronborg C, Vass M, Lauridsen J, Avlund K: Cost effectiveness of preventive home visits to the elderly: economic evaluation alongside randomized controlled study. Eur J Heal Econ 2006, 7(4):238-246.

52. Korthals-de Bos IBC, Smidt N, van Tulder MW, Rutten-van Molken MPMH, Ader HJ, van der Windt DAWM, Assendelft WJJ, Bouter LM: Cost 
effectiveness of interventions for lateral epicondylitis: results from a randomised controlled trial in primary care. Pharmacoeconomics 2004, 22(3):185-195.

53. Bjorkdahl A, Nilsson AL, Grimby G, Sunnerhagen KS: Does a short period of rehabilitation in the home setting facilitate functioning after stroke? A randomized controlled trial.[Erratum appears in Clin Rehabil. 2007 Mar;21(3):287]. Clin Rehabil 2006, 20(12):1038-1049.

54. Brainsky A, Glick H, Lydick E, Epstein R, Fox KM, Hawkes W, Kashner TM, Zimmerman SI, Magaziner J: The economic cost of hip fractures in community-dwelling older adults: a prospective study. J Am Geriatr Soc 1997, 45(3):281-287.

55. Whitlatch CJ, Feinberg LF: Family and friends as respite providers. J Aging Soc Policy 2006, 18(3-4):127-139.

56. Wiktorowicz ME, Goeree R, Papaioannou A, Adachi JD, Papadimitropoulos E: Economic implications of hip fracture: health service use, institutional care and cost in Canada. Osteoporos Int 2001, 12(4):271-278.

57. Chung RY, Tin KY, Cowling BJ, Chan KP, Chan WM, Lo SV, Leung GM: Longterm care cost drivers and expenditure projection to 2036 in Hong Kong. BMC Heal Serv Res 2009, 9:172.

58. Robertson MC, Devlin N, Gardner MM, Campbell AJ: Effectiveness and economic evaluation of a nurse delivered home exercise programme to prevent falls. 1: Randomised controlled trial. BMJ 2001, 322(7288):697-701.

59. Campbell AJ, Robertson MC, La Grow SJ, Kerse NM, Sanderson GF, Jacobs RJ, Sharp DM, Hale LA: Randomised controlled trial of prevention of falls in people aged $>$ or $=75$ with severe visual impairment: the VIP trial. BMJ 2005, 331(7520):817.

doi:10.1186/1472-6963-13-69

Cite this article as: Farag et al:: A systematic review of the unit costs of allied health and community services used by older people in Australia. BMC Health Services Research 2013 13:69.

\section{Submit your next manuscript to BioMed Central and take full advantage of:}

- Convenient online submission

- Thorough peer review

- No space constraints or color figure charges

- Immediate publication on acceptance

- Inclusion in PubMed, CAS, Scopus and Google Scholar

- Research which is freely available for redistribution 